\title{
Reply to: "Cytoreductive Surgery (CRS) and Hyperthermic Intraperitoneal Chemotherapy (HIPEC) Definitively Does Not Deserve Its Bad Reputation"
}

\author{
Philipp Horvath, $\mathrm{MD}^{1,2}$, and Can Yurttas, $\mathrm{MD}^{1,2}$ \\ ${ }^{1}$ Department of General, Visceral and Transplant Surgery, Comprehensive Cancer Center, University of Tübingen, \\ Tübingen, Germany; ${ }^{2}$ National Center for Pleura and Peritoneum, University of Tübingen, Tübingen, Germany
}

It is with great interest that we read the letter to the Editor from Noiret et al. and the associated publication. ${ }^{1}$ We are very pleased to have the opportunity to frame an answer.

The results from Noiret et al. ${ }^{1}$ illustrate very impressively the impact of center experience (cut-off $>45$ procedures/year) on postoperative mortality. Another important issue reported by the authors is that high-volume centers experienced increased major morbidity but had a significantly lower FTR index. On the other hand, the authors provided from their point of view several conceptual frailties of our previous study. ${ }^{2}$ The main difference between those two publications ${ }^{1,2}$ is the frame of the database. The data from our study were extracted from the nationwide German diagnosis-related group (DRG) statistics hosted by the German Federal Statistics Office. This is not a prospective database containing all the variables of interest in the context of PSM treatment. The database only contains clinical information necessary for DRG- and costrefund calculations. Noiret et al. are absolutely right that, in our publication, several highly interesting parameters (PCI scores, CC scores, degree of experience with PSM treatment, and the respective case load per year) were missing. This was unfortunately due to the frame of the database. On the other hand, the prospective database (PSMI) seemed to provide a lot more clinically relevant

(c) The Author(s) 2021

First Received: 4 February 2021

Accepted: 5 February 2021;

Published Online: 26 February 2021

P. Horvath, MD

e-mail: Philipp.horvath@med.uni-tuebingen.de information, and therefore Noiret et al. answered a variety of important questions in the context of PSM treatment, which could not be addressed by us.

Our conclusion that the reduction of the FTR index was due to a higher degree of centralization of PSM treatment was an assumption underlined by the fact that CRS and HIPEC procedures in Germany should only be performed in centers of excellence or competence, and from 2009 to 2018, a lot of centers were certified. The Deutsche Gesellschaft für Allgemein- und Viszeralchirurgie (DGAV, German Association of General and Visceral Surgery) provides a certificate only to centers that fulfill certain requirements (i.e., case load/year).

Overall, we are absolutely in line with the conclusion from Noiret et al. that these publications reporting on almost 16,000 patients should redefine the view on CRS and HIPEC procedures. Hopefully, we will see a decrease in the reluctance of some physicians to refer patients to high-volume centers for evaluation of CRS and HIPEC.

FUNDING Open Access funding enabled and organized by Projekt DEAL.

DISCLOSURE The authors have no conflicts of interest.

OPEN ACCESS This article is licensed under a Creative Commons Attribution 4.0 International License, which permits use, sharing, adaptation, distribution and reproduction in any medium or format, as long as you give appropriate credit to the original author(s) and the source, provide a link to the Creative Commons licence, and indicate if changes were made. The images or other third party material in this article are included in the article's Creative Commons licence, unless indicated otherwise in a credit line to the material. If material is not included in the article's Creative Commons licence and your intended 
use is not permitted by statutory regulation or exceeds the permitted use, you will need to obtain permission directly from the copyright holder. To view a copy of this licence, visit http://creativecommons. org/licenses/by/4.0/.

\section{REFERENCES}

1. Noiret B, Clement G, Lenne X, Bruandet A, Glehen O, Voron T, et al. Centralization and oncologic training reduce postoperative morbidity and failure-to-rescue rates after cytoreductive surgery and hyperthermic intraperitoneal chemotherapy for peritoneal surface malignancies: study on a 10-year national French practice. Ann Surg. 2020;272(5):847-54.

2. Überrück L, Nadiradze G, Yurttas C, Königsrainer A, Königsrainer I, Horvath P. In-hospital mortality and complication rates according to health insurance data in patients undergoing hyperthermic intraperitoneal chemotherapy for peritoneal surface malignancies in Germany. Ann Surg Oncol. 2020. https://doi.org/ 10.1245/s10434-020-09301-z.

Publisher's Note Springer Nature remains neutral with regard to jurisdictional claims in published maps and institutional affiliations. 